\title{
Correctional Practitioners on Reentry: A Missed Perspective
}

\author{
ELAINE GUNNISON, JACQUELINE B. HELFGOTT \& CECILIE WILHELM \\ Seattle University
}

\begin{abstract}
Much of the literature on reentry of formerly incarcerated individuals revolves around discussions of failures they incur during reintegration or the identification of needs and challenges that they have during reentry from the perspective of community corrections officers. The present research fills a gap in the reentry literature by examining the needs and challenges of formerly incarcerated individuals and what makes for reentry success from the perspective of correctional practitioners (i.e., wardens and non-wardens). The views of correctional practitioners are important to understand the level of organizational commitment to reentry and the ways in which social distance between correctional professionals and their clients may impact reentry success. This research reports on the results from an email survey distributed to a national sample of correctional officials listed in the American Correctional Association, 2012 Directory. Specifically, correctional officials were asked to report on needs and challenges facing formerly incarcerated individuals, define success, identify factors related to successful reentry, recount success stories, and report what could be done to assist them in successful outcomes. Housing and employment were raised by wardens and corrections officials as important needs for successful reentry. Corrections officials adopted organizational and systems perspectives in their responses and had differing opinions about social distance. Policy implications are presented.
\end{abstract}

\section{Keywords: Reentry; Practitioners; Success; Corrections Officials; Wardens}

Reentry is a pressing issue at the forefront of corrections today. In 2013, just under 7 million persons were serving under some form of correctional supervision (i.e., prison, jail, probation, and parole) (Glaze \& Kaeble, 2014). Of that total, approximately 1.2 million individuals were serving sentences in prison. Every day in the United States, 1,800 adults $(600,000$ annually) leave federal and state prisons and return to society (Carson \& Sobel, 2012). Each day these individuals attempt to successfully reintegrate back into their communities. However, successful reentry is an elusive goal for many given the almost insurmountable obstacles facing them (Gunnison \& Helfgott, 2013; Petersilia, 2003). Research on reentry over the past thirty years has demonstrated that formerly incarcerated persons' ability to reintegrate successfully is hindered by numerous obstacles such as difficulty in obtaining employment, acquiring housing, and being admitted to higher education (Allender, 2004; Cowan \& Fionda, 1994; Delgado, 2012; Harlow, 2003; Harris \& Keller, 2005; Hunt, Bowers, \& Miller, 1973; Latessa, 2012;
Nagin \& Waldfogel, 1993; Paylor, 1995; Pinard, 2010; Rodriguez \& Brown, 2003; Starr, 2002; Whelan, 1973); many also have serious social and medical problems (Petersilia, 2003). Newly released persons encounter stigmatization (Bahn \& Davis, 1991; Funk, 2004; Steffensmeier \& Kramer, 1980; Tewksbury, 2005), lose social standing in their communities (Chiricos, Jackson, \& Waldo, 1972), and are in need of social support (Berg \& Huebner, 2010; Cullen, 1994; La Vigne, Visher, \& Castro, 2004; Lurigio, 1996) as well as substance abuse and mental health treatment (Petersilia, 2003). Thus, successful reintegration of formerly incarcerated persons into the community is critical if reductions in recidivism are to be achieved (Gunnison \& Helfgott, 2013; Shinkfield \& Graffam, 2009).

Several researchers have explored whether criminal justice professionals are aware of the needs and challenges formerly incarcerated persons face upon reentry (Brown, 2004a; Brown, 2004b; Graffam et al., 2004; Gunnison \& Helfgott, 2007; Gunnison \& Helfgott 2013; Helfgott, 1997; Helfgott \& Gunnison, 2008). 
For instance, Brown (2004a) examined perceptions of federal parole officers regarding formerly federally incarcerated persons' needs in Canada, and Graffam and colleagues (2004) examined criminal justice professionals' perceptions of formerly incarcerated persons' needs in Melbourne, Australia. Additionally, Gunnison \& Helfgott (2007) examined community correction officers' $(\mathrm{CCO})^{1}$ perceptions of the needs of formerly incarcerated individuals, the value officers placed on the specific needs, and the opportunities available to meet their needs in Seattle, Washington. More recently, Lutze (2014) provided a comprehensive examination of the professional lives of CCOs and their critical involvement in reentry success. Describing CCOs as "street-level boundary spanners," Lutze (2014, p. xii) offers a detailed account of how individuals in the CCO role provide necessary links that cut across criminal justice, social service, and mental health systems. This attention to the $\mathrm{CCO}$ role and perspective in the reentry process is a critical missing piece in understanding the complexities of reentry success. To date, the research exploring criminal justice professionals' perceptions of needs and challenges has focused specifically on CCOs, but has not on perspectives of other correctional professionals, such as correctional superintendents and wardens, correctional counselors, or other correctional personnel.

This study builds on previous research (Brown 2004a; Brown 2004b; Graffam et al., 2004; Gunnison \& Helfgott, 2007; Gunnison \& Helfgott 2013; Helfgott, 1997; Helfgott \& Gunnison, 2008; Lutze, 2014) to fill the gap in the literature by examining the needs and challenges of formerly incarcerated individuals and successful reentry from correctional officials across the nationwardens and non-wardens. The perspectives on successful reentry from these professionals have not been heard to date. While some may argue that warden and superintendent perspectives are not directly relevant in the reentry literature because these executive correctional administrators do not interface with the delivery of reentry programs, this is a misconception. "Leaders of state and federal institutions define and set the tone for what constitutes success and how systems may collaborate to provide essential services to achieve shared goals" (Lutze, 2014, p. 240-241). Reentry success depends on buy-in from all levels of correctional administration and staff to ensure continuity of reentry efforts

1 CCOs refer to employees in the court and correctional systems who monitor both pre-sentenced and sentenced persons in the community (e.g., probation and parole offenders) to ensure that they are complying with regulations, such as obtaining employment and refraining from criminal activity, and assist their clients in gaining access to programming that they need (e.g., drug and/or alcohol treatment). All CCOs receive training as part of their jobs and their educational backgrounds vary from those who are only high school educated to those that are college graduates. across prison and community corrections contexts with "continuum of care beginning the first day of incarceration, flowing into community supervision, and solidifying in the community long-term" (Lutze, 2014, p. 256). Thus, the views of correctional administrators regarding reentry are ultimately as critical as line-level community corrections personnel in implementing system-wide reentry programs that span and are supported within institutional and community corrections contexts. Additionally, this research further examines the narratives of these officials from an organizational and systems theory perspective with attention to the ways in which social distance (Helfgott \& Gunnison, 2008; Jones, 2004; Schnittker, 2004) may impact the ability of correctional professionals to assist formerly incarcerated individuals in the reentry process.

\section{Literature Review}

With the passage of legislation in the United States (U.S.) designed to assist formerly incarcerated persons in successful reintegration from prison into their communities and discussions by international scholars of new legislation in countries, such as Serbia, that aim to reduce recidivism in these newly released individuals, the topic of reentry resonates across international borders (Batricevic \& Ilijic, 2013; Bureau of Justice Assistance, 2011). Utilizing research studies from both U.S. and international scholars, the following sections provide an overview of what formerly incarcerated persons need during reentry as well as the views that correctional professionals have about what is needed to enhance reentry success. The views of both correctional professionals and formerly incarcerated individuals are important to investigate when it comes to examining reentry. A shared understanding of the needs and challenges that these persons face in the transition from incarceration to community life among line-staff and administrative correctional professionals, as well as between them and their families, have the potential to enhance reentry success. From an organizational and systems theory perspective, all players and structures within the criminal justice system are interconnected and ideally work together to perform the function of criminal justice. Gibbs (1970) describes an organization as a creation to achieve means for specified objectives or outcomes. Its design determines how goals are subdivided and emulated within subdivisions of the organization. Therefore, these divisions, departments, sections, positions, jobs, and tasks make up the work structure or work group. Furthermore, within the criminal justice system, there are various levels within the 
structure with the goal of positive outcomes. As seen through the interaction of the offender with the criminal justice system, he or she is input into the criminal justice system via an act of criminality, and then processed into some form of correction, and the anticipated goal is the output of a non-offender. Additionally, criminal cases processed within the criminal justice system not only include the offender; the victim and the general public are a part of the systems as noted in outputs such as increased safety and retribution. Any defective products of the criminal justice system would be those of re-offending offenders and dissatisfied victims (Benard, Paoline, \& Pare, 2005). Thus, the shared goals among professionals across components of the criminal justice as well as shared goals among administrative-level and line corrections personnel has the potential to improve reentry success (Bernard et al., 2005; DeMichele, 2014; Gibbs, 1970; Giblin, 2013; Kraska \& Brent, 2011;National Research Council; 2004).

Issues of technology transfer, however, whereby administrators and line-level staff are disconnected can be a hindrance to successful rehabilitation (Gendreau, Goggin, \& Smith, 1999). After all, if correctional administrators are expecting their employees to both know and follow principles of effective rehabilitation, but they are not, then it is likely that reentry will not be successful. Additionally, on a broader cultural level, social distance and the view of formerly incarcerated persons as "other" (e.g., not "normal;" antisocial; or lower in social status) is a feature of the late modern culture of control (Garland, 2001) that can be seen as the antithesis of the creation of opportunities for these individuals to succeed in the reentry process. Furthermore, as the individual is perceived as the "other" and thus a member of the marginalized and criminalized populations, they have very little political power or voice including public sympathy when it comes to providing more opportunity such as social services for a successful reentry (Garland, 2001).

\section{Needs and Obstacles in the Reentry Process}

Over the past several decades, research has emerged, in the United States and across the world, that has identified critical needs that formerly incarcerated individuals have during reentry as well as some of the obstacles that they face trying to fulfill their needs. Reentry needs consistently identified in the literature include housing, employment, and substance abuse treatment (Gunnison \& Helfgott, 2013; Petersilia, 2003). Housing has been identified as one of the most difficult obstacles that these persons face (Corden, Kuipers, \& Wilson, 1978; Cowan \& Fionda, 1994; Graffam et al., 2004; Paylor,
1995; Roman \& Travis, 2004; Starr, 2002). Limited credit, rental history, finances, and the tendency for property managers to conduct background checks and to deny housing to particular types of persons, severely reduces housing opportunities for formerly incarcerated persons (Helfgott, 1997). While legislation was passed in the United Kingdom in 2002 to assist formerly incarcerated persons in gaining access to housing, barriers still remain ranging from limitations to where they may reside to availability of housing options (Gojkovic, Mills, \& Meek, 2012). Newly released persons cite employment as another primary obstacle in the reentry process (Latessa, 2012; Visher, Baer, \& Naser, 2006). Many must rely on personal connections to find a job (Visher, LaVigne, \& Travis, 2004) and attempts to secure employment are often thwarted by legal barriers (Harris \& Keller, 2005) and employer unwillingness to hire them (Holzer, Raphael, \& Stoll, 2003). In an examination of employment legislation for twelve countries in the European Union, for instance, Loucks, Lyner, and Sullivan (1998) found that a criminal record was a substantial barrier for formerly incarcerated persons in gaining employment. More recently, Pijoan (2014) reports that this is still a problem and states that there is an increased use of criminal background checks for employment in continental Europe. Employment discrimination for formerly incarcerated persons has been found in other countries such as Australia (Saliba, 2013). Drug addiction is a struggle for many of these individuals (Mallik-Kane \& Visher; 2008; McKean \& Raphael, 2002), many of whom are in need of mental health support (Lurigio, 1996; Mallik-Kane \& Visher, 2008) and may resort to drastic measures such as suicide in response to the stress (Biles, Harding, \& Walker, 1999). Formerly incarcerated persons need assistance with the prevention of relapse into alcohol and/or drug use (Mallik-Kane \& Visher, 2008; Prendergast, Wellisch, \& Wong, 1996). Such assistance, mental health treatment and relapse support, is particularly important as social support can contribute to successful reintegration (Cullen, 1994; Hepburn \& Griffin, 2004; Mallik-Kane \& Visher, 2008). Also of consideration are the legal penalties placed upon them known as "collateral consequences [that] burden individuals long past the expiration of their sentences and which, individually and collectively, frustrate their ability to move past their criminal records" (Pinard, 2010, p. 1214). These collateral consequences are defined as ineligibility for the following: federal welfare benefits; government assisted housing; jury service; restriction from certain types of employment and licensing; restriction from military service; sex offender registration and voting 
disenfranchisement. It should be noted that these consequences not only affect the formerly incarcerated individual, they also create an impact upon their families and communities - thus exasperating an already difficult reentry for them into the community (Pinard, 2010).

The high level of need for social services and assistance one year after release such as housing-assistance, job training, education, medical assistance, and general financial support and the difficulty in obtaining such services can make reentry into society very difficult (Visher, 2007). Also, consequences due to limited access to resources impact not only the formerly incarcerated individual and his/her family; it can also affect mainstream society. For example, from 1982- 2005, U.S. taxpayers experienced a $700 \%$ increase in spending for corrections, from $\$ 9$ billion to over $\$ 65$ billion. This is reflective of the inability for many to reintegrate into society as a result of limited access to social service benefits (Mouzon, 2008).

With a dearth of knowledge that has emerged on reentry due to not only researcher interest but also the availability of federally supported research investigations on reentry, much has been learned beyond needs and challenges of formerly incarcerated persons reentering society (Miller, 2014). For example, reentry success, or the ability of these persons to reintegrate successfully into society following incarceration, may depend on the availability of programming to assist those considered high risk as well as aftercare provided in the community to these individuals (Bouffard \& Bergeron, 2006; Miller \& Miller, 2010). Despite such gains in knowledge, much of the research on reentry has focused on defining success as "recidivism" which often leads to an incomplete understanding of reentry (Miller, 2014).

\section{Correctional Perspectives on Needs and Challenges}

Similar to research emerging on reentry, over the past decade, research has emerged on state and federal correctional officers' perspectives about the needs and challenges formerly incarcerated individuals have during reentry (Brown, 2004a; Brown, 2004b; Graffam et al., 2004; Gunnison \& Helfgott, 2007; Gunnison \& Helfgott 2013; Helfgott, 1997; Helfgott \& Gunnison, 2008). In 2002, Seiter examined 114 state parole officers in Missouri as to their perceptions of what is important to reentry and how their own job contributions could be a factor in successful reintegration. Consistent with previous needs pinpointed in the empirical literature, the parole officers identified employment, abstaining from drugs, and social support as important needs.
The officers believed that they could help facilitate reentry by establishing close surveillance of the parolees, assisting parolees in maintaining employment, and referring parolees to community agencies that would meet their needs. Additionally, Brown (2004a; 2004b) examined perceptions of 74 federal parole officers regarding formerly federally incarcerated persons' needs and challenges in the first 90 days of release in Canada. Officers identified food, clothing, shelter, transportation, life skills, education, and employment assistance as the most important needs that parolees have when first released. Officers stated that the challenges they faced included: establishing family support, readjusting to non-institutional life, financial problems, lack of employment experience, stigma, and lack of access to programming.

In a study of 132 state and federal CCOs in Seattle, Washington, Gunnison and Helfgott (2007) reported the top five needs that CCOs identified that newly released persons face are shelter/housing, job placement services, knowledge of the crime cycle, having a realistic community plan, and understanding risk factors. Further, officers reported the following challenges that newly released persons face upon release as the top five: finding shelter/housing, returning to substance abuse, being accustomed to getting money easily through illegal means, returning to dysfunctional families, and developing positive associations. In a 1997 study, Helfgott, who interviewed formerly incarcerated persons about their needs, reported that they believed that their CCOs did not truly understand their needs and did not see their CCOs as a resource in the reentry process. One subject stated, "they [CCOs] just want you to tell a good lie...they have no understanding of what it's like...take them out [of their environment] and they wouldn't be able to survive on the streets" (Helfgott, 1997, p. 16). Yet, Helfgott's (1997) study did not examine CCOs' views of reentry needs as well as their perception of whether or not officer-client social distance ${ }^{2}$ influences the reentry process. This idea of CCO and client social distance was explored in subsequent research investigations with CCOs. For example, in another study on CCO perceptions, Helfgott and Gunnison (2008) found that social distance was significantly related to officer identification of some needs and challenges, and offi-

\footnotetext{
2 "Social distance" has been defined in the research literature as and the level of trust one group has for another (Schnittker, 2004) and the degree of perceived similarity of beliefs between a perceiver and target (Jones, 2004). Several scales in the institutional corrections literature have been developed to measure social distance between officers and offenders (e.g., Hepburn, 1984; Klofas \& Toch, 1982). However, no clear consensus exists regarding the definition or measurement of officer-client social distance.
} 
cer attitudes toward their clients. However, from the officers' perspective, social distance did not appear to play a large role in officer ability to identify reentry needs. Officers did not collectively perceive officer-client social distance as a hindrance in the reentry process and suggested that their clients may use the notion of social distance as an excuse not to change. To further explore CCOs' perspectives on reentry, Gunnison and Helfgott (2011) reported results from narrative survey responses from state and federal CCOs. Some CCOs reported that successful reentry is due to a rational decision to change. For instance, one officer reported, "Prosocial living is a choice just as crime and drug use is a choice" (Gunnison \& Helfgott, 2011, p. 295). Another theme that emerged from the research revolved around officer attitude. That is, the CCOs' attitude may contribute to or hinder reentry success. As one officer stated, "Sometimes depends on the CCO if they have a superior attitude or not, if the $\mathrm{CCO}$ believes he/she is better than the offender, then offender will see that and act accordingly" (Gunnison \& Helfgott, 2011, p. 296). This statement suggests that if CCOs view the formerly incarcerated person as the "other," then perhaps they will be unable to help their clients. When the CCOs were asked whether social distance played a role in reentry success, they overwhelmingly reported that it did not In response to this question, one officer reported, "No! The offenders will find all kinds of excuses to lurk behind. It's the offenders that would want to change and the community corrections officer's situation does not matter here" (Gunnison \& Helfgott, 2011, p. 295). Therefore, this statement emphatically displays the belief there is not social distance in the relationship between the $\mathrm{CCO}$ and formerly incarcerated individual; it is the formerly incarcerated individual's motivation to change rather than the influence of the $\mathrm{CCO}$ rather than social distance.

More recently, Gunnison and Helfgott (2013), in a qualitative study, interviewed 19 CCOs on their perceptions of reentry success and probed CCOs about what is needed to foster reentry success. The researchers began with asking the CCOs to define "success." Some CCOs reported the lack of re-offending as success while others mentioned that success is when there are small improvements in the life of the formerly incarcerated individual. That is, not all CCOs viewed success in terms of recidivism. Additionally, the researchers reported that CCOs cited factors such as housing, family support, sobriety, and mental health assistance as the foundation pieces to successful reentry. One of the CCOs described how having a basic need met, such as housing, can free formerly incarcerated persons to focus on what they need to do to be successful:

What is huge for this population in particular is housing; I mean that is important for any one, but when you're working with people who have chronic mental illness and such a lengthy history, it is another compounding factor that keeps them from doing well in addition to being a convicted felon, in addition to having a history of homelessness; then they have this chronic mental illness and probably, maybe a drug or alcohol addiction with it. . . . I've seen housing be an amazing component to someone's success and turn people's lives around in a way you never thought...like a motel room would even do (Gunnison \& Helfgott, 2013, p. 152).

The researchers also asked CCOs how they contribute to success. Many CCOs reported that building trust, establishing rapport, and guiding clients towards resources were ways in which they contributed to reentry success. With regard to social distance, several CCOs in their research investigation believed that the perceptions of social distance by formerly incarcerated individuals about their CCOs may be due to the nature of the CCOs' role - to maintain professional boundaries between themselves and their clients. Other CCOs did acknowledge that their clients may perceive social distance, but that the CCOs work to break down these barriers through establishing good communication and rapport with them. Gunnison and Helfgott (2013) reported that beyond the needs (i.e., housing, employment, treatment) being met, CCOs mentioned that formerly incarcerated persons' willingness to change as well as having a good social support structure are critical to fostering successful reentry. Lutze (2014) explains that when the perspective of CCOs is examined, it becomes clear that community supervision of clients is a complex endeavor; it involves multiple approaches that straddle a broad range of criminal and social justice and community agencies, and, ultimately, community corrections and reentry is a human business characterized by the success and depth of interpersonal relationships.

There has been very limited research conducted on correctional perspectives of reentry outside the U.S., and the scant research that does exist has centered on probation officers' views of their needs. For example, McNeill (2000), who interviewed 12 probation officers in Scotland, reported that the officers emphasized meeting the needs of their clients as one key to promoting probation effectiveness. However, in an examination of 15 French probation officers, Herzog-Evans 
(2011) found that probation officers had had no knowledge about what needs their clients had or how they could even assist their clients. In fact, many officers felt nothing could be done for their clients and viewed that their role was to give their client a push towards law-abiding behavior when it seemed like they were ready for such a push. This finding suggests a problem with technology transfer. On the other hand, in an analysis of 300 intervention plans created by probation officers in the Netherlands, Bosker, Witteman, and Hermanns (2013) found that officers are aware of needs that should be met for their clients as they administer a risk assessment instrument to their clients. However, the officers' intervention plans often fail to address the identified needs - suggesting again a problem with technology transfer or disconnect between knowledge and intervention plans that could promote desistance.

The present study seeks to fill the gap in the literature by examining successful reentry from the perspective of correctional officials in administrative and other professional roles across the nation-wardens and non-wardens. The perspectives on successful reentry from these professionals (i.e., wardens or upper level administrators) have not been heard to date. Additionally, moving beyond examining reentry through the lens of recidivism, the researchers asked the respondents to report on the needs and challenges facing formerly incarcerated individuals, define success, discuss social distance, describe how they may have contributed to their success, identify factors that may contribute to success, and report on what needs to be done right now to foster successful reentry. Further, the researchers examine their responses to ascertain how their narratives fit within the existing organizational and system perspectives and whether they adopt the view of formerly incarcerated persons as "other."

\section{Method}

To explore the needs and challenges of those reentering society, reentry success, and what is needed today for successful reentry, this research investigation required the inclusion of multiple practitioners in the corrections field to garner their perspectives. Through such an investigation, this research study seeks to contribute to the understanding of the needs and challenges faced by formerly incarcerated persons and the identification of successful reentry factors.

\section{Sample}

The data used in the following analyses are gathered from a voluntary self-report survey that was e-mailed to $904^{3}$ correctional workers (i.e., wardens and non-wardens) across the nation via Survey Monkey ${ }^{4}$. Specifically, this survey collected responses from a national pool of correctional staff including wardens, superintendents, chaplains, social workers, counselors, and correctional officers from adult and juvenile prison facilities. The e-mail addresses ${ }^{5}$ were obtained from the American Correctional Association, 2012 Directory. This directory lists individuals by name and position (ex. warden, prison chaplain, etc.) along with their contact information (i.e., e-mail address) for each state. Before data collection began, approval from the Institutional Review Board at Seattle University was granted.

The first surveys were e-mailed to wardens and superintendents from January to March of $2013^{6}$. Following the survey administration to administrators, a second, and final, wave of surveys were e-mailed to correctional staff from June to September of 2013. After the survey was first e-mailed for each wave, two subsequent e-mail reminders were e-mailed to the sample pool in hopes of garnering more participation. While the survey response rate was low at $12.7 \%$, it is not unexpected as e-mailed surveys historically yield low response rates (Bachman \& Schutt 2013). The following sections describe the demographics of all 71 respondents for both waves and then demographics for the respondents who identified as wardens $(n=49)$ or superintendents and those who did not identify as wardens or superintendents $(n=22)$ (See Table 1).

Overall, for the 71 participants who completed the survey, the majority were White $(73 \%)$, male $(51 \%)$, indicated they held a bachelor's degree as their highest level of education (47\%), worked in the corrections field before their current position $(75 \%)$, and had

\footnotetext{
3 This number includes the total number of working e-mail addresses that the survey was sent to. An additional 103 surveys were e-mailed to participants but the e-mails bounced back to us. Thus, we have excluded these from our total possible sample size count.
}

4 Note: The researchers were members of the ACA and had access to the national database as part of the membership. The researchers are academics and not correctional professionals although they have many years of experience conducting research in correctional facilities.

5 The researchers tried to purchase all of the e-mail addresses for American Correctional Association (ACA) members, but this was not an option made available by the ACA. Therefore, a research assistant created a nationwide database of e-mail addresses that were published in the directory. The unavailability of a full list of ACA member e-mails very much limited our sample size.

6 When the authors first e-mailed the surveys to participants, some states (e.g., Tennessee, Michigan, Washington) would not allow their employees to participate in the survey unless the authors went through a separate state Research Review/Institutional Review Board (IRB) process even though the project had already been approved by the IRB at Seattle University. Such state Department of Corrections policies resulted in a further limitation to the sample size since not all 50 states could be included. Specifically, the exclusion by these states further limited our total sample size by 48 participants which resulted in our final sample size of 904. It is unknown as to whether such policies also contributed to no responses from employees in other states. 
worked in their position for $1-5$ years $(47 \%)$. The ages of the total sample ranged from 33 years to 69 years of age with the average age being 51 . The total number of years of service that the participants had worked in the correctional field prior to the current position was as follows: $7 \%$ held $1-5$ years of service; $7 \%$ held $6-10$ years of service; $16 \%$ held $11-15$ years of service; $17 \%$ held 16-20 years of service; and 30\% held 21 years or more of service. The majority of participants worked in a state facility at $87 \%$ while only $3 \%$ worked in a non-governmental facility.

For the 49 participants who identified as wardens or superintendents who completed the survey, the majority were White (84\%), male (53\%), indicated they held a bachelor's degree as their highest level of education $(58 \%)^{7}$, worked in the corrections field before their current position (88\%), and had worked in their position for $1-5$ years $(61 \%)$. The age of participants ranged from 38 years of age to 62 years of age with average

Table 1

Demographics for ACA National Pooled Respondents

\begin{tabular}{|c|c|c|c|}
\hline & $\begin{array}{l}\text { Wardens } \\
(\mathrm{N}=49)\end{array}$ & $\begin{array}{l}\text { Non-Wardens } \\
(\mathrm{N}=22)\end{array}$ & $\begin{array}{l}\text { Overall } \\
(\mathrm{N}=71)\end{array}$ \\
\hline \multicolumn{4}{|l|}{ Race/Ethnicity } \\
\hline Black & $9.3 \%$ & $13.6 \%$ & $9.9 \%$ \\
\hline White & $83.7 \%$ & $72.7 \%$ & $73.2 \%$ \\
\hline Asian & $2.3 \%$ & $0.0 \%$ & $1.4 \%$ \\
\hline American Indian & $0.0 \%$ & $0.0 \%$ & $0.0 \%$ \\
\hline Hispanic & $2.3 \%$ & $4.5 \%$ & $2.8 \%$ \\
\hline Bi-Racial & $0.0 \%$ & $4.5 \%$ & $1.4 \%$ \\
\hline Other & $2.3 \%$ & $4.5 \%$ & $2.8 \%$ \\
\hline \multicolumn{4}{|l|}{ Educational Status } \\
\hline High School & $4.7 \%$ & $0.0 \%$ & $2.8 \%$ \\
\hline GED & $0.0 \%$ & $0.0 \%$ & $0.0 \%$ \\
\hline Tech School & $0.0 \%$ & $0.0 \%$ & $0.0 \%$ \\
\hline Tech Diploma & $0.0 \%$ & $0.0 \%$ & $0.0 \%$ \\
\hline Some College & $0.0 \%$ & $9.1 \%$ & $2.8 \%$ \\
\hline Associates & $0.0 \%$ & $4.5 \%$ & $1.4 \%$ \\
\hline BA & $58.1 \%$ & $36.4 \%$ & $46.5 \%$ \\
\hline MA & $37.2 \%$ & $50.0 \%$ & $38.0 \%$ \\
\hline \multicolumn{4}{|l|}{ Gender } \\
\hline Male & $53.5 \%$ & $59.1 \%$ & $50.7 \%$ \\
\hline Female & $46.5 \%$ & $40.9 \%$ & $40.8 \%$ \\
\hline \multicolumn{4}{|c|}{ Current Employer Status } \\
\hline State & $97.6 \%$ & $95.5 \%$ & $87.3 \%$ \\
\hline Federal & $0.0 \%$ & $0.0 \%$ & $0.0 \%$ \\
\hline \multicolumn{4}{|c|}{ Previous Correctional Work Experience } \\
\hline No & $11.6 \%$ & $31.8 \%$ & $16.9 \%$ \\
\hline Yes & $88.4 \%$ & $68.2 \%$ & $74 . \%$ \\
\hline \multicolumn{4}{|c|}{$\begin{array}{l}\text { Years in Correctional Field Prior to } \\
\text { Current Position }\end{array}$} \\
\hline 0 & $0.0 \%$ & $0.0 \%$ & $0.0 \%$ \\
\hline $1-5$ & $5.1 \%$ & $20.0 \%$ & $7.0 \%$ \\
\hline $6-10$ & $5.1 \%$ & $20.0 \%$ & $7.0 \%$ \\
\hline $11-15$ & $17.9 \%$ & $26.7 \%$ & $15.5 \%$ \\
\hline $16-20$ & $20.5 \%$ & $26.7 \%$ & $16.9 \%$ \\
\hline 21 years or more & $51.3 \%$ & $6.7 \%$ & $29.6 \%$ \\
\hline
\end{tabular}


age being 50. The total number of years of service that the participants had worked in the correctional field prior to the current position was as follows: $5 \%$ held 1-5 years of service; $5 \%$ held $6-10$ years of service; $18 \%$ held $11-15$ years of service; $20 \%$ held $16-20$ years of service; and $51 \%$ held 21 or more years of service. The majority of participants $(98 \%)$ worked in a state facility while only $2 \%$ worked in a non-governmental facility.

Of the 22 participants who were identified as non-wardens who completed the survey,

the majority were White $(73 \%)$, male $(59 \%)$, indicated they held a Master's degree as their highest level of education (58\%), worked in the corrections field before their current position (68\%), and had worked in their position for 6-10 years (32\%). The age of participants ranged from 33 years of age to 69 years of age with the average age being 51 . The total number of years of service that the participants had worked in the correctional field prior to the current position was as follows: $20 \%$ held $1-5$ years of service; $27 \%$ held $6-10$ years of service; $27 \%$ held $11-15$ years of service; and $7 \%$ held 16-20 years of service. The majority of participants $(96 \%)$ worked in a state facility while only $4 \%$ worked in a non-governmental facility.

The survey instrument had a total of 14 open-ended questions that asked subjects about ex-offender re-entry. Participants were queried about the needs and challenges ex-offenders have upon release, their definitions of ex-offender reentry success, how they can contribute to success, inhibitors to success, factors that foster success, the role of social distance, and what is needed to better help ex-offenders during reentry (See Table 2). Through a process of narrative analysis, the responses of the survey from the 22 correctional staff and 49 wardens and superintendents were inductively evaluated in search of common themes. ${ }^{8}$ Each response was read several times, labeled, coded per theme noted, and then entered in SPSS to determine frequency of theme per respondent through a descriptive analysis. Additionally, themes were explored further through the inspection of open-ended responses.

The analyses proceeded in several stages. First, all data was entered into SPSS, and then frequencies for all variables including the narrative responses were run. For all the remaining data that was narrative, the researchers reviewed and inspected the responses for each question line by line and applied code to key words and phrases. Then, the researchers counted the

8 While the survey did allow for the survey respondent to provide his/her contact information in order for the researchers to engage in follow-up interviews, very few participants provided this information. Thus, the researchers were unable to engage participants in follow-up conversations. frequency of the occurrence for the key word or phrase for the individual question. The researchers also applied the same approach when examining narratives that were indicative of an organizational and systems perspective as well as views of formerly incarcerated persons.

\section{Results}

The results are presented within themes that emerged from the data 9 . For both correctional administrators (i.e., wardens and superintendents) and correctional line staff, we report on their perceptions of the needs and challenges faced by formerly incarcerated persons during reentry. Next, we report on the how both groups adopted an organizational and systems perspective in response to our questions. Then, we report on the perspectives that both groups had of formerly incarcerated individuals to ascertain whether they viewed them as "other." Finally, we investigated the similarities and differences between the two samples in regard to their responses.

\section{Correctional Administrator (Warden and Superin- tendent) Perspectives of Needs}

The researchers asked correctional administrators about their views of the needs and challenges faced by formerly incarcerated persons during reentry and asked them to recall some examples of those who had successfully reintegrated back into their communities. When asked about the needs their clients had upon re-entry, wardens and supervisors identified employment as the most important need after release at $76 \%$, followed by the need for housing at $67 \%$ (See Table 3 ). Other important needs were identified such as community corrections at $45 \%$ and support from family at $41 \%$. Challenges often experienced by formerly incarcerated persons upon re-entry were described as limited or no employment at $58 \%$, limited or no housing at $40 \%$, no acceptance from family and community at $35 \%$, associating with friends in deviant networks at $23 \%$, and limited or no coping skills at $23 \%$.

As noted, employment and housing, followed by family support are important factors in facilitating successful reentry for the individual. One warden described the short-term and long term needs for formerly incarcerated persons as follows:

Immediate needs are to secure appropriate housing, family re-integration, employment (application, interviewing techniques), job leads. Longer-term needs include NA/AA counseling, family counseling, life skills

9 Note: To preserve the integrity of the data, all participant responses were used without editing. Thus, any typos or misspellings observed are part of the original responses. 
Table 2

Survey Instrument

1) What needs do ex-offenders have upon reentry? Please specify both immediate (i.e., within 90 days of release)
and longer-term needs (i.e., 6 months to one year later). Also, please be as exhaustive as possible in your listing of
needs. Feel free to add any additional comments regarding the factors that you identified.

2) What challenges do ex-offenders have upon reentry? Please specify both immediate (i.e., within 90 days of release) and longer-term challenges (i.e., 6 months to one year later). Also, please be as exhaustive as possible in your listing of challenges. Feel free to add any additional comments regarding the factors that you identified.

3) What recollections of success stories do you have? Please provide a number count of how many ex-offenders successful reentry stories you can recall and provide a few examples of stories of successful ex-offender reentry. Also, please specify is these offenders were probationers, parolees, work release clients, etc. , their criminal offense, as well as any demographics that you can recall about the offender such as approximate age, race/ethnicity, and gender.

4) How do you think you contributed to the success of the offenders you have worked with who have succeeded in the reentry process?

5) How do you personally define reentry success?

6) Describe your personal style of interaction with ex-offenders.

7) How does your above-mentioned interaction with offenders impact offender success upon release?

8) What factor(s) can you identify that inhibit successful ex-offender reentry? Please be as exhaustive as possible in your listing of responses. Feel free to add any additional comments regarding the factors that you identified. Please note if any of your identified factors differ by the types of crime that offender may have committed or by demographics such as gender, race/ethnicity, or socioeconomic status.

9) What factor(s) can you identify that enhance successful ex-offender reentry? Please be as exhaustive as possible in your listing of responses. Feel free to add any additional comments regarding the factors that you identified. Please note if any of your identified factors differ by the types of crime that offender may have committed or by demographics such as gender, race/ethnicity, or socioeconomic status.

10) In situations where there are opportunities in the community for ex-offenders to meet the above identified needs, but offenders do not take advantage of the opportunities and are not able to create "niches" in the community to enhance their success, what do you see as the primary factor obstructing offenders' ability to get their needs met?

11) What are your general thoughts about what should be done in your community to deal with offenders who re-enter the community upon release from a period of incarceration? What gaps exist or hinder successful ex-offender transition?

12) Previous research has suggested that some offenders feel that their community corrections officers do not understand their situations because they come from very different social backgrounds. We are interested to get your perspective on this issue. Is social distance (differences in past experiences, economic circumstances, drug/alcohol use, etc) between offenders and community corrections officers a problem that hinders offenders success upon release?

13) What barriers do you face in your job that inhibits your ability to foster successful ex-offender reentry?

14) If you were to ask for one thing that would make your job easier in enhancing ex-offender success upon release, what would it be?

\section{training.}

Another warden poignantly mentioned that they have:

Every need you and I have. Clothing, housing, medications, transportation, employment, health care, pro-social contacts and activities.

Given that successful reentry is difficult, not surprisingly, many wardens in our sample had difficulties in recalling success stories. For those who were able to recall success stories, the following factors for a suc- cessful outcome were identified as: placement into employment (44\%); education (31\%); and support from family, faith, support groups, and corrections (28\%). Finally, volunteering within the community or prison environment was also identified as a contributor to successful reentry (19\%). For example, wardens reported,

Most successful stories I have heard are due to their age. Most offenders who began their criminal beginnings at a young age, by the time they reach their 50 's are less likely to return. For example, I have an offend- 
Table 3

Correctional Administrator (Warden and Superintendent) Perspectives of Needs \& Challenges

\begin{tabular}{lll}
\hline \multicolumn{1}{c}{ Needs } & & \\
Code & Category & \\
Fam & Family & $41 \%$ \\
CommCo & Community Corrections & $45 \%$ \\
House & Housing & $67 \%$ \\
Employ & Employment & $76 \%$ \\
& & \\
Challenges & & \\
Code & Category & $23 \%$ \\
NoCope & Limited or No Coping skills & $23 \%$ \\
BadFriends & Bad Friends, Old networks & $40 \%$ \\
NoHouse & Limited or No Housing & $58 \%$ \\
NoEmploy & Limited or No Employment & $35 \%$ \\
Stigma & No Acceptance from Family and Community \\
\hline
\end{tabular}

er in the 80's, 90's and 2000's, for selling drugs. Each time he was release he returned to the same neighborhood, and had the same acquaintances, until their acquaintances moved or died and they became older, their crime stopped.

I worked with an offender who was doing very poorly on supervision. He was using drugs regularly, stealing from his supportive others, engaging in violent behavior. Complicating matters, he was hearing impaired and did not know sign language. We were at the point we were recommending revocation because we were concerned about community safety. His supportive other called me and asked for another chance. He was able to get into an AODA program, we were able to get him a hearing device that was able to amplify sound enough for him to use and we were able to enroll him in sign language classes. He excelled in the program and we worked to give him positive feedback on his progress. I get a card from him every year telling me that he is doing great and thanks me for giving him another chance. He was a probationer, on for burglary, while male in his late 20's.

Although successful reentry is possible, there are various factors that the wardens and superintendents identified as inhibitors. For example, $29 \%$ noted that associating with deviant social networks contributed to unsuccessful reentry. Limited access to counseling or therapy was determined to be an inhibiting factor at $22 \%$ as well as a bad attitude, lack of support from family, community, and corrections, and limited employment at $21 \%$. Finally, the "offender type" was an inhibiting factor or collateral consequence dependent upon the type of offense, disabilities, age, gender, and race as well. One participant reported, "Females generally get lower paying jobs out of prison. Sex Offenders can't find employment or housing." Another participant, referencing age and type of crime committed, reported,

The younger the inmate, the harder for them to achieve positive habits. I know this theory is opposite from what most experts feel as the general thought is "the younger person can change their habits easier than an older person". However, I view the younger person has less motivation to conform, feel they are less "cool", and they do not get notices and praised by peers unless they are acting out. I have also witnessed those incarcerated for Murder are most often our best inmates and if these individuals do get released, are more likely to succeed. Those who commit some robberies and all sex crimes tend to be impulsive and cause more problems. Also, those who have drug/stimulant dependency.

Other wardens reported,

Those offenders released to a large inner city in my opinion are more likely to return than those who live in rural areas. The offenders in rural areas are predominantly white and those released to larger metropolitan areas appear to be African American.

Unobtainable goals; minimizing their responsibility; portraying themselves as victim; negative attitudes; substance abuse; mental illness; lack of pro-social support from friends and family. 
Offender is unwilling to change, lack of resources (e.g. money to have enough staff to appropriately case plan with offenders, not enough money to address programming needs of the offenders, not enough money to utilize current technology, etc.), lack of understanding from the judicial system on risk/needs assessments and what they mean, who is at risk to reoffend and how to appropriately "treat" them, lack of understanding from the legislature on needing to fund us so we can provide those things that "work" to reduce recidivism so we aren't dealing with the revolving door, lack of training in evidenced based approaches, not training corrections officers on motivational interviewing techniques, not building accountability into employee position descriptions and performance evaluations, not enough emphasis on department mission statement how peoples job responsibilities tie into the mission, agencies operating in silos rather than cooperatively, underutilization of stakeholders (e.g. old belief that we can do it ourselves), offering programs that have little impact on recidivism, not addressing gender responsive or cultural needs, not receiving visits while incarcerated.

I believe that African Americans definitely have a harder time obtaining jobs upon release mainly due to lack of help from friends, relative, former employers in addition to just their race.

Substance abuse, not finding employment, not connected to community - having someone to rely on for support in re-entry i.e. mentors; faith community; support group.

Attitude, motivation, drive, all have a big role in their success. If a young man believes that they can't achieve anything or do anymore than they currently are they will never become more. They also have to learn new ways to respond to challenging situations instead of being reactive. They have to learn to think before reacting. Sometimes that requires additional counseling and medication in the community.

Wardens and superintendents were then asked to identify primary factors obstructing the formerly incarcerated persons' ability to get their needs met. No motivation was noted as the highest factor at $36 \%$, with a lack of support from family and community at $18 \%$, followed by deviant social networks and bad attitude at $13 \%$. One warden explained,

This is probably the most disheartening part of working in corrections. We have programs, services and re- sources available that we know work and inmates don't take advantage of them. I think most inmates think they will do things differently once they are released but fail to understand the impact of their environment and culture that led to their incarceration.

Other wardens reported,

You can lead a horse to water but you can't make them drink. Typically the individual is their own worst enemy. They have to want something different, not just say they want something different, but truly want it from deep inside. If they really want it and it is available they will involve themselves in it. Other obstacles are time management and transportation. Just because they are available doesn't mean they are easy to access because of transportation issues or how it fits into their lives (job, family, school, etc.).

People cannot be motivated unless they have a desire to do better. Primary factor obstructing is their own lack of responsibility.

They do not have a strong enough desire to lead a crime free lifestyle or do not have the skills necessary to engage in a pro-social lifestyle.

Correctional administrators' responses indicate that they are indeed aware of the needs and challenges faced by formerly incarcerated persons during reentry. However, a few responses from administrators indicated that they had indeed adopted an organizational and system perspective on reentry and that perhaps some of their views regarding one's attitude, such as formerly incarcerated persons being "their own worst enemy," may suggest a view of them as "other."

\section{Correctional Administrator Organizational and Systems Perspectives on Reentry}

The wardens and superintendents were asked to define how they may have contributed to the success of the formerly incarcerated persons in the stories recounted, what successful reentry meant to them, to describe the barriers they faced in their jobs, as well as what could make their job of enhancing successful reentry easier. Upon analyzing their responses to these questions, many in the sample adopted an organizational or systems perspective.

With regard to how the participants may have contributed to the success of formerly incarcerated persons, they identified factors such as being a role model and providing education (46\%), providing resources and links to resources $(44 \%)$, earning and treating inmates with respect (24\%), and motivating ex-offenders 
(20\%). However, some admitted that they played no direct role or could not take credit while others claimed that a team approach and hiring staff (providing resources, allowing creativity), influencing policy, and programming contributed. Thus, several of the responses were consistent with the adoption of an organizational or systems perspective. For instance, wardens reported,

I believe it is a team effort that makes it success happen. It usually isn't just one person.

My education, training, and utilization of effective interventions. My belief that it is my role to assist the offenders in a way that helps them "stay out" of prison once they are out. Targeting offenders antisocial attitudes, associates, and personality. Treating them humanly. Holding them accountable for their "negative" behaviors. Rewarding their "positive" behaviors. Treating them humanely. Not giving up on them when they have given up on themselves. Believing that the offender can change if they are given the skill sets and have the desire to make changes. The offenders knew I liked my job, they knew I wanted them to be successful.

Consistent with previous research on narrative definitions of success, successful reentry was defined as exhibiting prosocial behavior $(61 \%)$ and no recidivism $(56 \%)$. Many referred to the three year standard measure of recidivism, but not all embraced that definition. Responses to our question of success included:

An offender who never comes back into the system. Forget the three year time frames. WE aren't successful unless he never comes back into the system.

Reentry success has to have a time line. We have recidivism which is measured out 3 years. If we don't have an inmate return in 3 years - it is a success. On a smaller scale, offenders completing a transition program and now residing on their own is a success.I also look at 6 months after their final release from a facility and those who have not been rearrested are a success.

I don't like to define success in terms of recidivism (however you might define that). I like to define success in terms of the individual person. For example, if I have a person who was very defiant and closed, and they begin to open up and work on their problems - I think that is a success. If it is a person who had a lot of needs, but they remained vigilant in addressing those needs - that is a success.
Correctional administrators' responses suggest that they adopt an organizational systems perspective on reentry. For example, comments by administrators that for reentry to be successful it takes a team approach suggest that these administrators view successful reentry with a systems approach rather than an individualistic one. Also, their adoption of the absence of recidivism as the measure of "success" is consistent with how the overall correctional system views success (i.e., recidivism).

\section{Correctional Administrator (Warden and Superin- tendents) Perspectives about Formerly Incarcerat- ed Persons}

The warden and superintendents were questioned about their personal interactions with offenders in an effort to determine if their descriptions of their interactions with their clients depicted a view of the formerly incarcerated persons that reflected social distance and a view of the formerly incarcerated individual as "other." Most of the correctional administrators viewed their interactions with formerly incarcerated persons as being professional, hands on, a good listener, approachable, and firm and fair. Thus, administrators saw their interactions with formerly incarcerated persons as professional. For instance, wardens reported,

Firm, fair, consistent. I am not afraid to challenge their thinking errors, distortions, tactics. I express empathy when appropriate. I use humor when appropriate. I allow them time to talk. I believe good boundaries means it is my job to know what is going on with offenders, they just don't need to know that information about me. If I don't know the answer to something - I tell them that. I don't make promises I can't keep. I believe in integrity. I role model the behavior I expect of them. When they have stepped over a boundary, I don't hesitate to tell them. I believe in the 4:1 ratio (4 positives for every negative). I try to identify what stage of change they are in, and use skill sets (e.g motivational interviewing, effective case planning strategies) to move them along the continuum.

I draw on the personal experience of ex-offenders to help guide me in the decision making process. Ex-offenders can tell me what works and what doesn't. They can explain what their needs are and what causes them to return to prison. Ex-offenders need to be part of the solution.

You need to have great listening skills. You need to be able to communicate and treat the inmate with re- 
spect. Be honest, set goals for the inmate, and make sure you show appreciation for their accomplishments. I contributed to their success by remembering they are human beings that made mistakes and trying not to judge them but to instill in them to look to the future. I managed a work release center for 9 years and assisted men in obtaining employment, housing and referring them to support agencies on the street that would help them succeed. My standard message was, "You can't change what happened yesterday, you can only change what you want to do tomorrow.

These responses reveal conflicting messages about formerly incarcerated individuals including references that may be seen as a view of the formerly incarcerated as having a character deficit potentially rooted in social disadvantage while also reflecting a humanistic and empathetic approach. For example, the warden who mentioned using a "firm, fair, and consistent" approach clearly articulates professional officer-client interaction. However, reference to the formerly incarcerated as using thinking errors and distortions and the need to have good boundaries could be said to imply a sort of social-distancing whereby the officer maintains professional boundaries with the client while utilizing organizational terminology to treat the client in a particular ("firm, fair, and consistent") manner. On the other hand, some of the wardens noted that the unique experience of the formerly incarcerated is an asset in the reentry process that correctional professionals need to make use of in conjunction with a humanistic, respectful approach. This suggests that the correctional professional views include both elements of social distancing as well as an understanding and empathetic approach that recognizes how the unique experience of the formerly incarcerated can be utilized as a strength rather than a deficit in the reentry process.

Wardens were specifically asked about the role of social distance between CCOs and their clients to determine how they see differences between themselves and the formerly incarcerated as impacting their ability to assist in the reentry process. The majority of respondents $(57 \%)$ reported that they thought social distance was not an issue hindering reentry success. One warden respondent offers his perspective on the issue of social distance,

No. BUT, lack of empathy for where a person came from is a problem that hinders success. First of all, that research is clearly flawed because it is dealing with an offenders perception that their agent did not have the same social obstacles. An agent does not share their personal stories of upbringing, economic status and drug and alcohol history. I have found that if an agent listens, tries to understand and tries to motivate a person to change for the better, the relationship is positive and strong.

Thus, the warden discounted social distance as an issue, suggesting that regardless of differences in backgrounds between officers and their clients, an approach to clients that involves empathy is critical to reentry success.

The correctional administrators saw their role as assisting the formerly incarcerated in whatever way they could. They did not view social distance between

Table 4

Correctional Line-Staff Perspectives of Needs \& Challenges

\begin{tabular}{lll}
\hline$\underline{\text { Needs }}$ & & \\
Code & Category & \\
Support & Support/Faith/Groups & $38 \%$ \\
CouTher & Counseling/Therapy & $43 \%$ \\
Med & Medical Treatment/Medication & $43 \%$ \\
House & Housing & $81 \%$ \\
Transp & Transportation & $38 \%$ \\
Employ & Employment & $76 \%$ \\
& & \\
Challenges & & \\
Code & Category & $32 \%$ \\
BadNeig & Bad Neighborhoods & $23 \%$ \\
BadFam & Issues with Family or No Family Support \\
BadFriends & Bad Friends, Old networks & $28 \%$ \\
NoHouse & Limited or No Housing & $41 \%$ \\
NoEmploy & Limited or No Employment & $73 \%$ \\
\hline
\end{tabular}


CCOs and their clients as inhibiting reentry. However, the tone of their responses indicated that they saw their clients as "other" in the sense of having to maintain strong boundaries while having an empathetic approach in their interactions.

\section{Correctional Line-Staff Perspectives of Needs}

Correctional staff were questioned about the needs that formerly incarcerated persons have upon re-entry (See Table 4). They reported that housing was the most important need after release $(81 \%)$ followed by the need for employment (76\%). Other important needs were identified such as continued counseling and therapy as well as medical treatment and medication at $43 \%$. Support from family, community, and corrections as well as reliable transportation were also noted as necessities (38\%). The correctional staff reported many challenges faced upon reentry including limited or no employment $(73 \%)$, limited or no housing $(41 \%)$, residing in bad neighborhoods (32\%), associating with friends in deviant networks $(28 \%)$, and issues with family or no family support (23\%).

Housing is an important factor in facilitating a successful reentry for the formerly incarcerated persons. Corrections officials reported,

Housing, many offenders don't have a relationship with family any longer and have no place to go and no money to get housing. Of course we try to place them but due to some crimes this isn't possible.

Many offenders are homeless so I would say housing is the number one need. Our half-way houses are closed due to budget cuts and our homeless shelters can only take so many offenders.

For formerly incarcerated persons to be successful during reentry, the correctional staff survey participants identified several factors that were related to success. The participants identified the availability of legal financial resources $(63 \%)$, desistance from substance abuse (38\%) and support from family, faith, support groups, and corrections (31\%) as being important for successful reentry. Additionally, they reported that strong coping skills were also a contributor to success $(27 \%)$. Many of the correctional staff were hard pressed to recall success stories. Either there were too few to recount or they did not track client outcomes. As one correctional staff mentioned, "The success stories in my thirty plus years are few and far between. Most inmates that I have witnessed not come back have aged out and are on some sort of public assistance."
One correctional staff, who could recall many successes, discussed legal means of financial resources and support from family as being critical,

Approx. 10-15 success that I know about. Most are due to family support, both emotional and financial. One offender was able to go home to his wife and to a job with his father and brother. As far as I know he has been successful for the 5-6 years. Another had a business that his son kept going and owned his house and has been successful for approx 9 years.

Another correctional staff participant reported that strong coping skills are necessary to face the challenges of reentry. The staff participant stated,

I can recall two successful reentry occurrences. Both were parole violators... He had some mental problems but had a strong sense of faith that helped him cope greatly. He experienced severe attacks on his life on two occasions. Through mental health counseling, cognitive skills training and reentry classes he gained the tools to be successful. (offender 2) He gained them because he internalized the information and applied them to his life and current situations. There are various factors that can inhibit a successful re-entry. Correctional staff identified the following as inhibitors: issues with families or no family support (33\%); associating with deviant social networks (33\%); lack of support from support groups and community stigmatization (28\%); and substance abuse relapse (22\%).

The correctional staff participants described support from family, faith and support groups, and corrections an important factor in successful reentry (63\%). Other important factors that they identified included employment $(47 \%)$ and access to community and personal resources $(42 \%)$. All three factors were noted by one correctional staff member when asked about what factors are needed for successful reentry,

Support, support, support and employment. Daycare for women to leave their children. Counseling for both sexes as well as gang prevention/intervention, as well groups relating to understanding people of different ethnicities.

Other participants reported,

A welcoming home situation. The household and ex-offender realize that former roles and current roles will need to be redefined. A receptive community that 
is willing to receive a former offender. Involvement in a supportive community of faith. Employers willing to hire ex-offenders.

Adequate planning, developing realistic and appropriate goals. Community support as well as family support. Motivation. Friends and family who are supportive and provide encouragement. The availability of Academic and Employment opportunities.

Correctional staff were then asked to identify primary factors obstructing the formerly incarcerated person's ability to get their needs met. The participants reported that factors were lack of motivation by the individual (48\%), prideful behavior and issues with family (24\%), and low self-esteem and deviant social networks (19\%). One participant explains,

Pride, not being able to ask for the help that would otherwise help them be successful. For those that are more entitlement-driven in their perspective, they seem to be more demanding, wanting the resource to provide more for them individually than they are eligible to receive. This is what I have gleaned from the inmate that return and are discussing with me their pitfalls while they were out on the streets. No support, no transportation are barriers as well as feelings that ethnic groups are not well represented in the opportunities presented.

Another correctional staff participant references the preference of a deviant lifestyle and lack of motivation as inhibitors to success, "They do not want to change. The benefits of a criminal lifestyle outweigh a prosocial lifestyle for them."

Correctional line-staff responses indicated that they are indeed aware of the needs and challenges faced by formerly incarcerated persons during reentry. However, a few responses from this group reflect the adoption of an organizational and system perspective on reentry that maintains a social distance and deficit view of the formerly incarcerated. For example, views about the formerly incarcerated as needing support, having low self-esteem, being entitlement-driven, or wanting more assistance than they are due, suggests a deficit view of the formerly incarcerated that can be seen as a form of "othering" that may have an impact on the experience of the formerly incarcerated in the reentry process.

\section{Correctional Line-Staff Organizational and Sys- tems Perspectives on Reentry}

The correctional line-staff were asked to define how they may have contributed to the success of the former- ly incarcerated in the stories recounted what successful reentry meant to them, to describe the barriers they faced in their jobs, as well as could make their job of enhancing successful reentry for formerly incarcerated persons easier. Upon analyzing their responses to these questions, many in the sample adopted an organizational or systems perspective.

When asked about the barriers they faced in their jobs, as well as what could make their job easier in enhancing successful re-entry for the ex-offender, correctional staff identified limited resources (25\%), limited staff (20\%), and time constraints (15\%) as barriers to fostering successful ex-offender re-entry. Specifically, correctional line staff reported,

Lack of resources not being able to track these individuals by providing evidence based programs that will ensure success.

We are locked into a box with few programs. Materials and resources are available but we need staff to be more educated about re-entry.

Powerlessness in follow-up and the economic climate, as well as political Leaders wanting to lock up offenders and throw away the key versus treatment and rehabilitation.

Time, never enough. Resources, the lack of them. Contact in the communities across the state, building them takes time and a lot of effort.

To enhance successful reentry, correctional staff described the ability to follow up with ex-offenders (19\%), community outreach, (15\%), and more resources $(10 \%)$ as critical factors. Correctional staff reported,

The ability to follow up to see how the inmate is progressing. We have Fraternization policies.

Long term sober living housing to give the offenders a fresh start and not return them to the same place they came from. Many times your setting them up to fail. More resources, programs that actually deal with addiction/substance abuse, resources center for ex-offenders to utilize once released and when struggling, mentor programs.

Correctional line-staff responses suggest that they adopt an organizational systems perspective on reentry. For example, comments by administrators that for reentry to be successful it will take more resources, 
materials, and leaders that adopt a more rehabilitative perspective towards reentry is needed for reentry to be successful. Additionally, the acknowledgement by one respondent who mentions that "you are setting them up to fail" reflects the view that perhaps the system, as it currently is working, is broken and that it is the system itself that is hindering successful reentry.

\section{Correctional Line-Staff Perspectives about For- merly Incarcerated Persons}

The correctional staff participants described their personal interactions with formerly incarcerated persons as motivating (31\%), developing trust $(31 \%)$ and serving as a role model $(27 \%)$. In their descriptions of their interactions, their responses indicated support for formerly incarcerated persons. Correctional staff reported,

I am down to earth, and honest. I talk to them and treat them with respect. I am firm, fair and consistent.

I personally try and be a role model that shows an offender that I truly do care about his success while in prison and after his release. I try to be person that doesn't treat them like they are a "nobody", that they are somebody and they can make a difference.

This aforementioned response further highlights the professional boundary-setting and empathetic approach taken by correctional staff toward the formerly incarcerated. The staff-member here articulates an attempt to treat the client like a "somebody," however the approach reinforces what might be seen a form of empathetic organizational distancing seen as necessary by correctional staff in their interactions with clients.

In fact, one correctional line staff, when reflecting on what can be done in the community to assist formerly incarcerated persons successfully reenter society, reports,

Community re-entry programs which include churches, community centers, victims, and citizens with open minds to embrace these individuals. Gaps that hinder successful transition are individual with closed minds who don't believe that people can change.

In regard to the lack of community acceptance, one staff explains the role of stigmatization,

The stigma of ex-offenders is still very alive and well. No one wants a half-way house or group home in their neighborhood. We could well benefit from neighborhood awareness of the challenges of ex-offenders and the real concerns of the citizens. If society could look past what they have done and focus on what the ex-offenders could offer the community, it would be helpful. Most older citizens are not as open to change and acceptance of people who have made mistakes. Sex Offenders face a greater challenge and in some cases there can be a real concern. I might add that the employees of the group homes and half-way houses have to be actively involved and have a vested interest in the ex-offenders. This is perhaps a very unrealistic view, but a hope for the future one.

In order to ascertain whether social distance exists between community correctional officers their clients, as reported in previous research, participants were asked if social distance exists. A total of $64 \%$ of participants felt there was a level of social distance between CCOs and their clients. This finding contrasts with some of the correctional administrators' opinions indicating that they did not believe that there was social distance between CCOS and their clients. One correctional line staff respondent describes this view of social distance as having a necessary but negligible role in the officer-client dynamic,

That has to be assumed, unless the officer is a former thief, drug-user, etc. their individual perspectives will be poles apart. Not having the handicap of a criminal past, the officer is not going to be on the same wave length as the parolee, that disconnect will always be a part of the problem, although a necessary one. It will be the same hindrance that I have in working with these guys behind the walls, if they won't follow the few, basic rules that we have inside, how do they think they will be successful dealing with the world on the outside?

Another agrees that social distance is apparent and highlights the need to make use of formerly incarcerated individuals who have similar backgrounds to their clients as an aid in the reentry process.

I believe we need to use more ex-offenders with proven track records in non-custody type positions as substance abuse counselors, case managers, counselors, re-entry coaches. Most of my friends who work in this areado not have a clue as to what an offender faces on the outside. Some do not care.

When reflecting on the narratives of the correctional administrators, they saw their role as assisting the formerly incarcerated by being role models and mo- 
tivating them. A sizeable majority of the correctional line-staff did think that social distance was an issue between CCOs and their clients. Respondents viewed stigmatization of formerly incarcerated persons as another problem. Again, these views reinforce the notion that the formerly incarcerated have character deficits and are socially disadvantaged while at the same time are in need of understanding, empathy, role modeling, and motivation. This is a complex and in some respects contradictory view of the formerly incarcerated whereby correctional line-staff see their formerly incarcerated clients as "other" while at the same time noting that in order for reentry to be successful, interactions with the formerly incarcerated must also involve understanding and empathy.

\section{Common Themes and Differences among Wardens and Non-Wardens}

Upon further inspection of the participant data, there were some commonalities in responses as well as some differences between wardens and correctional linestaff. When asked to define the needs and challenges of formerly incarcerated persons upon reentry, both housing and employment were important needs for them identified by both wardens and correctional staff. Similarly, both wardens and non-wardens identified challenges faced by formerly incarcerated persons during reentry to be limited housing, limited employment, and bad friends or old (social) networks. Interestingly, both wardens and non-wardens raised concerns about enhanced difficulties during reentry experienced by both formerly incarcerated females and those incarcerated for sex offenses. Wardens also specifically mentioned difficulties for formerly incarcerated African-Americans in securing employment. Both groups articulated that support was important for successful reentry-although each group viewed support in a different way. Wardens believed that support is an important factor that should come from the family; however, correctional staff believed that support should come in the form of assistance. Additionally, both correctional administrators and correctional line-staff adopted organizational and systems perspectives on reentry. A few differences, however, emerged between the groups. While wardens and superintendents thought more transitional programs would be helpful to foster successful reentry, correctional line-staff believed having the ability to follow up with formerly incarcerated individuals would be an important factor. Moreover, some of the correctional administrators did not perceive that social distance between CCOS and their clients was a hindrance in the reentry process. However, their responses depict a dichotomous approach to their clients -- a socially disadvantaged formerly incarcerated individual in need of the professional assistance of an empathetic role model. This sets up an inherent dynamic in the officer-client relationship that organizationally institutionalizes a view of the formerly incarcerated person as "other."

\section{Organizational Institutionalization of the Other}

The responses of the correctional professionals reveal conflicting views of the formerly incarcerated. On one hand, the correctional administrators and staff view formerly incarcerated persons as lacking skills or referring to their character in some manner, thereby, adopting a deficit view. For instance, correctional administrators and staff identified clients' deficits as "substance abuse" and "mental illness" while also noting that character deficits such as "negative attitudes," "motivation," "drive," and lack of rule following as inhibitors to reentry success for those formerly incarcerated. On the other hand, the correctional administrators and staff described that the formerly incarcerated lack larger structural supports such as friends and family, housing, programmatic resources, and community supports. For instance, the administrators and staff had noted, "many offenders are homeless," "not having someone to rely on for support in re-entry," that there is a "lack of understanding from the legislature on needing to fund us," and that community does not want "a halfway house or group home in their neighborhood." Additionally, the correctional administrators and staff acknowledged the value of seeing the formerly incarcerated as experts who can help other formerly incarcerated individuals in the reentry process. Statements such as, "Ex-offenders can tell me what works and what doesn't," and "Gaps that hinder successful transition are individuals with closed minds who don't believe that people can change" suggest understanding, empathy, and humanist views of formerly incarcerated persons. These conflicting views of the formerly incarcerated whereby correctional professionals see their clients as having a deficit, living within inadequate social structure, and being seen by the larger society as "nobodies" on the one hand, while recognizing the importance of an empathetic approach in dealing with the formerly incarcerated characterize the correctional professionals' view of the formerly incarcerated as the other.

\section{Discussion}

The results from this study offer perspectives and insights from correctional wardens/superintendents 
and correctional staff - an important missing piece in the literature on reentry success to enhance work that has previously examined views of CCOs (Brown, 2004a; Brown, 2004b; Graffam et al., 2004; Gunnison \& Helfgott, 2007; Gunnison \& Helfgott 2013; Helfgott, 1997; Helfgott \& Gunnison, 2008; Lutze, 2014). Lutze's (2014) important work on CCOs' professional lives as the "invisible side of reentry" highlights the need to recognize how system dysfunction can hinder reentry success and how the support, tools, education, and incentives available to CCOs in their everyday working realities impacts their ability to implement evidence-based practice in reentry. The correctional administrators and line-staff views presented here echo the need for shared organizational and system-wide definitions and goals such as shared definitions of measures of recidivism in relation to reentry (e.g., recognition that definitions of recidivism that focus solely on re-offense and reconviction without attention to smaller personal changes offenders may make that may result in longer time periods between offenses). The results presented here add the additional missing perspective of correctional administrators and staff in both institutional and community corrections contexts. Lutze (2014, p. 259) notes:

Considering the perspective of CCOs offers the reminder that community supervision is a human business concerned with success and depth of interpersonal relationships... Understanding the reality of work ing with offenders, who to CCOs are not just abstract statistics to be managed but complex individuals who also experience the joy of success and the agony of defeat, brings one closer to realizing that CCO's work cannot be easily categorized but instead exists on a continuum. CCO's decisions are influenced by the quality of the human relationships in which they engage and whether they trust the potential effective ness of providing support, treatment, sanctions, or some combination of the three.

One of the most problematic issues in the reentry process is the disconnection between institutional and community contexts. Understanding the perspectives of correctional professionals in diverse roles that span institutional and community corrections contexts adds an important additional element to understanding the ability of correctional professionals to implement evidence-based practice in offender reentry as well as provides an understanding for why these same professionals eschew early release policies even in light of current budget problems (Taxman, 2011). From a sys- tems perspective, as noted by the correctional professionals surveyed, in particular the line staff, the degree to which different components of the system are disconnected will be an obstacle to the reentry process.

The findings presented here indicate that despite popular belief, wardens are aware of their clients' needs and challenges. While wardens may not be in charge of overseeing correctional or reentry programming, the wardens in our sample were aware of the needs and the challenges that formerly incarcerated persons face, and that the perceived disconnect between top administrators and their front line staff may not exist. Additionally, the findings are consistent with past studies that have shown that housing and employment are recognized by CCOs as critical issues in reentry and that highlight distinct needs of specialized populations such as female offenders and those who served time for sex offenders and exacerbated discrimination faced by African American formerly incarcerated persons (Gunnison \& Helfgott, 2013; Holzer et al., 2003; Petersilia, 2003; Tewksbury et al., 2012). Concern expressed by wardens about African-Americans and employment was also a similar theme raised by CCOs in previous research. For instance, research has revealed that African-Americans face employment discrimination in getting hired and promoted (Holzer et al., 2003; Queralt, 1996). Further, several researchers have uncovered employment discrimination for African-Americans job applicants when compared to Caucasian job applicants (Beauchamp \& Bowie, 1993; Turner, Fix, \& Struyk, 1991; Weatherspoon, 1996). Findings also echo work by Clear (2007) highlighting issues with formerly incarcerated persons returning to disadvantaged communities and social environments.

Finally, the findings highlight the great need for resources (e.g., housing employment, programming), both in-house and in the community, in order to foster successful reentry.

The results presented here regarding the issue of social distance suggest that some correctional professionals believe social distance is inherent and, in some cases, a necessary part of the correctional role; however, they do not see social distance as a hindrance to the reentry process. Correctional professionals emphasize the need to see formerly incarcerated persons as human beings, and note the detriments to reentry associated with the stigmatization their clients experience in the community as dangerous others. The correctional professionals note the importance of developing rapport with their clients, especially in interactions where social distance issues are salient. Thus, the correctional professionals' responses reflect a nuanced understanding of the 
complex issues of social disadvantage, stigmatization, and social distance experienced by their clients. This unique understanding that correctional professionals have regarding the situations and experiences of their clients supports what some have observed as a cultural and historical shift that may be slowly occurring toward a more humanistic and empathetic correctional sentiment and a more restorative and community justice approach to reentry (Bazemore \& Boba, 2007; Bazemore \& Maruna, 2009; Bazemore \& Stichcomb, 2004; Clear, 2007; Clear, Hamilton, \& Cadora, 2010; Gunnison \& Helfgott, 2013, Helfgott, 2005; Settles, 2009, Swanson, 2009; Travis, 2001; 2005; Van Ness \& Strong, 2010) and away from the more punitive culture of control (Garland, 2001). However, the issue of what we have called institutionalized organizational "othering" is complex and needs to be further examined. Previous research indicating that formerly incarcerated experience themselves having an outsider identity and express concerns about the social distance between themselves and correctional professionals (Helfgott, 1997; Helfgott \& Gunnison, 2008) highlights the need to more fully understand how this negative experience of feeling "other" impacts the reentry process. The experience of feeling like an outsider or "other" can have many sources including negative or deficit views espoused by correctional staff as well as interactions that hold particular meaning for formerly incarcerated individuals as they experience social distance between themselves and correctional staff. Additional research is needed to further examine correctional professionals' perceptions of formerly incarcerated persons and how organizational and system elements contribute to reentry successes and failures. Furthermore, further examination of the ways organizational expectations and professional approaches may be changing in corrections and reentry in the United States is needed. Restorative correctional and reentry programs have been implemented in other countries in New Zealand, Australia, Canada, and Great Britain (Gunnison \& Helfgott, 2013). The views of correctional professionals presented here suggest that small steps may be occurring to identify system gaps that have historically hindered reentry success in the United States. Future research is needed to unpack the complex interpersonal and organizational dynamics that contribute to the formerly incarcerated individuals' experience of themselves as "other" and the elements of professional support help and hinder reentry success.

This study represents the first to examine the perspectives on formerly incarcerated persons reentry needs and success utilizing a sample of correctional pro- fessionals other than community corrections officers whose roles span institutional and community corrections contexts and staff and administrator roles. However, the current study is not without its limitations. First, sample size was a limitation in the study methodology. Our sample pool was limited as a result of difficulty in acquiring e-mail addresses for all corrections officials in the nation. Additionally, we had several incorrect e-mail addresses as e-mails were returned and reported as being unable to send. Further hindering our data collection efforts were various state policies that either prohibited the dissemination of our survey to correctional employees or disallowed employees from taking the survey. Second, while the sample included both wardens and non-wardens, our survey response rate was lower than desirable. E-mailed surveys tend to produce a low response rate (see Bachman \& Schutt, 2013). Third, while we offered respondents the opportunity to list their names and contact information for further follow-up conversations, very few opted to do so. This resulted in a limited amount of information that we were able to glean from open-ended typed comments.

Future research examining the views of correctional professionals that span institutional and community corrections contexts and administrator and staff roles will enhance understanding of system deficiencies and the capacity for individual correctional staff and administrators to implement evidence-based initiatives that enhance opportunities for successful reentry. As recognition of the importance of evidence-based practice increases, continued research examining the ways in which organizational culture, system characteristics, and interpersonal dynamics between correctional personnel and their formerly incarcerated impact the reentry process is needed. Further examination of the perspectives of correctional professionals in multiple jurisdictions with larger sample sizes, as well as the perspectives of other professionals in the criminal justice system regarding reentry, will continue to improve opportunities for reentry success.

\section{References}

Allender, D. M. (2004). Offender reentry: A returning or reformed criminal. FBI Law Enforcement Bulletin, 73, 1-10.

American Correctional Association. (2012). 2012 directory: Adult and juvenile correctional departments, institutions, agencies, and probation and parole authorities, $73^{\text {rd }}$ edition. Alexandria, VA: American Correctional Association.

Bachman, R., \& Schutt, R.K. (2013). The Practice of 
Research in Criminology and Criminal Justice, $5^{\text {th }}$ edition. Thousand Oaks, CA: Sage.

Bahn, C., \& Davis, L. (1991). Social-psychological ef fects of the status of probationer. Federal Probation, $55,17-25$.

Batricevic, A., \& Ilijic, L. (2013). Imprisonment in Sweden-normative frameworks, characteristics and impact on recividism. Journal of Criminalistics and Law, 18(2), 135-154.

Beauchamp, T. L., \& Bowie, N. E. (1993). Ethical the ory and business, 4th ed. Englewood

Cliffs, NJ: Prentice-Hall.

Bazemore, G., \& Boba, R. (2007). "Doing good" to "make good": Community theory for practice in a restorative justice civic engagement reentry model. Journal of Offender Rehabilitation, 46(1/2), 25-56. DOI: 10.1080/10509670802071493

Bazemore, G., \& Maruna, S. (2009). Restorative justice in the reentry context: Building new theory and expanding the evidence base. Victims and Offenders, 4, 375-384.

DOI: $10.1080 / 15564880903227446$

Bazemore, G., \& Stinchcomb, J. (2004). A civic engagement model of reentry: Involving community through service and restorative justice. Federal Probation, 68(2), 14-24.

Berg, M. T., \& Huebner, B. M. (2011). Reentry and the ties that bind: An examination of socialties, employment, and recidivism. Justice Quarterly, 28(2), 382-410.

DOI: $10.1080 / 07418825.2010 .498383$

Bernard, T. J., Paoline,, E. A., Pare, P. (2005). General systems theory and criminal justice. Journal of Criminal Justice. 33, 203-211. DOI: 10.1016/j.jcrimjus.2005.02.001

Biles, D., Harding, R., \& Walker, J. (1999). The deaths of offenders serving community corrections orders. Trends and Issues Australian Institute of Criminology, 107, 1-6.

Bosker, Jacqueline, Witteman, C., \& Hermanns, J. (2013). Do intervention plans meet criteria for effective practice to reduce recidivism? How probation officers forget about social capital and basic needs. European Journal of Probation, $5(1), 65-85$.

DOI: $10.1177 / 206622031300500105$

Bouffard, J. A., \& Bergeron, L. E. (2006). Reentry works: The implementation and effectiveness of a serious and violent offender reentry initiative. Journal of Offender Rehabilitation, 44, 1-29. DOI: 10.1300/J076v44n02_01

Brown, J. (2004a). Challenges facing Canadian federal offenders newly released to the community. Journal of Offender Rehabilitation, 39, 19-35. DOI: 10.1300/J076v39n01_02

Brown, J. (2004b). Managing the transition from jail to community: A Canadian parole officer perspective on the needs of newly released federal offenders" Western Criminology Review, 5, 97-107.

Bureau of Justice Assistance. (2011). Second Chance Act of 2007. Washington, DC: US Department of Justice.

Carson, E. A., \& Sobel, W. J. (2012). Prisoners in 2011. Washington D.C.: Bureau of Justice Statistics. http://www.bjs.gov/content/pub/pdf/p11. pdf

Chiricos, T., Jackson, P. \& Waldo, G. (1972). Inequality in the imposition of a criminal

label. Social Problems, 19, 553-572. DOI: http://dx. doi.org/10.2307/799931

Clear, T. R. (2007). Imprisoning communities: How mass incarceration makes disadvantaged neighborhoods worse. New York: Oxford University Press.

Clear, T. R., Hamilton, J. R., \& Cadora, E. (2002). Community justice. Cincinnati, $\mathrm{OH}$ :

Anderson.

Corden, J., Kuipers, J., \& Wilson, K. (1978). After prison: A study of the post-release experiences of discharged prisoners. Papers in community studies, 21. New York: University of York.

Cowan, D. S., \& Fionda, J. (1994). Meeting the need: The response of local authorities' housing departments to the housing of ex-offenders. British Journal of Criminology, 34, 444-458.

Cullen, F. T. (1994). Social support as an organizing concept for criminology: Presidential address to the Academy of Criminal Justice Sciences. Justice Quarterly, 11, 527-559.

Delgado, M. (2012). Prisoner reentry at work: Adding business to the mix. Boulder, CO: Lynne Rienner.

DeMichele, M. (2014). Studying the community corrections field: Applying neoinstitutional theories to a hidden element of mass social control. Theoretical Criminology. 18(4), 546-564. DOI: 10.1177/1362480614526276

Funk, P. (2004). On the effective use of stigma as a crime deterrent. European Economic Review, 48, 715-728. DOI: 10.1016/j.euroecorev.2003.11.003 Garland, D. (2001). The culture of control: Crime and social order in contemporary society. Chicago, IL: University of Chicago Press.

Gendreau, P., Goggin, C., \& Smith, P. (1999). The forgotten issue in effective correctional 
treatment: Program implementation. International Journal of Offender Therapy

and Comparative Criminology, 43(2), 180-187.

DOI: $10.1177 / 0306624 X 99432005$

Gibbs, C. A. (1970). Leadership: Selected Readings.

Harmondsworth: Penguin Books.

Giblin, M. J. (2013). Organization and management in the criminal justice system. Thousand

Oaks, CA: Sage.

Glaze, L. E., \& Kaeble, D. (2014). Correctional populations in the United States, 2013.

Washington, DC: Bureau of Justice Statistics, US Department of Justice.

Graffam, J., Shinkfield, A., Lavelle, B., \& McPherson, W. (2004). Variables affecting successful reintegration as perceived by offenders and professionals. Journal of Offender Rehabilitation, 40, 147-171. DOI: 10.1300/J076v40n01_08

Gojkovic, D., Mills, A., \& Meek, R. (2012). Accommodation for ex-offenders: Third sector housing advice and provision. Third Sector Research Centre Working Paper 77.

Gunnison, E., \& Helfgott, J. B. (2007). Community corrections officers' perceptions of exoffender reentry needs and challenges. Journal of Police and Criminal Psychology, 22(1), 10-

21. DOI: $10.1007 / \mathrm{s} 11896-007-9004-5$

Gunnison, E., \& Helfgott, J. B. (2011). Factors that hinder offender reentry success: A view from community corrections officers. International Journal of Offender Therapy and Comparative Criminology,55(2),287-304.DOI:10.1177/0306624X09360661 Gunnison, E., \& Helfgott, J. B. (2013). Offender reentry: Beyond crime and punishment.

Boulder, CO: Lynne Rienner.

Harlow, C. W. (2003). Education and correctional populations. Washington, D.C.: Bureau of Justice Statistics.

Harris, P. M., \& Keller, K. S. (2005). Ex-offenders need not apply: The criminal background check in hiring decisions. Journal of Contemporary Criminal Justice, 21, 6-30.

DOI: $10.1177 / 1043986204271678$

Helfgott, J. B. (1997). Ex-offender needs versus criminal opportunity in Seattle, Washington. Federal Probation, 61, 12-24. DOI: 10.1177/1043986204271678

Helfgott, J. B. (2005). Restorative justice. In M. Bosworth (ed.), Encyclopedia of prisons and correctional facilities (pp. 846-852). Thousand Oaks, CA: Sage. DOI:10.4135/9781412952514.n311

Helfgott, J. B., \& Gunnison, E. (2008). The influence of social distance on community corrections officer perceptions of offender reentry needs. Federal Probation, 1, 2-12.

Hepburn, J. R. (1984). The erosion of authority and the perceived legitimacy of inmate social protest: A study of prison guards. Journal of Criminal Justice, 12, 579-590.

DOI: $10.1016 / 0047-2352(84) 90115-6$

Hepburn, J. R., \& Griffin, M. L. (2004). The effect of social bonds on successful adjustment to probation: An event history analysis. Criminal Justice Review, 29, 46-75.

DOI: $10.1177 / 073401680402900105$

Herzog-Evans, M. (2011). Desisting in France: What probation officers know and do. A first approach. European Journal of Probation, 3(2), 2946. DOI: $10.1177 / 206622031100300203$

Holzer, H. J., Raphael, S., \& Stoll, M. A. (2003). Employer demand for ex-offenders: Recent evidence from Los Angeles. Unpublished manuscript.

Hunt, J. W., Bowers, J. E., \& Miller, N. (1973). Laws, licenses, and the offender's right to work: A study of state laws restricting the occupational licensing of former offenders.

Washington, DC: National Clearinghouse on Offender Employment Restrictions.

Jones, P. E. (2004). False consensus in social context: Differential projection and perceived social distance. British Journal of Social Psychology, 43, 417-429.

DOI: $10.1348 / 0144666042038015$

Klofas, J. M., \& Toch, H. (1982). The guard subculture myth. Journal of Research in Crime and Delinquency, 19, 238-254. DOI: 10.1177/002242788201900207 Latessa, E. (2012). Why work is important and how to improve the effectiveness of correctional reentry programs that target employment. Criminology and Public Policy, 11, 87-91. DOI:10.1111/j.1745-9133. 2012.00790.x.

La Vigne, N. G., Visher, C., \& Castro, J. (2004). Chicago prisoners' experiences returning home. The Urban Institute. Washington, D. C.

Loucks, Nancy, Lyner, O., \& Sullivan, T. (1998). The employment of people with criminal records in the European Union. European Journal on Criminal Policy and Research, 6, 195-210. DOI: 10.1023/A:1008632508533

Lurigio, A. J. (1996). "Responding to the mentally ill on probation and parole: Recommendations and action plans." In A. J. Lurigio (Ed.), Community corrections in America: New directions and sounder in vestments for persons with mental illness and codisorders (pp. 166-171). Seattle, WA: National Co- 
alition for Mental and Substance Abuse Health Care in the Justice System.

Lutze, F. E. (2014). The professional lives of community corrections officers: The invisible side of reentry. Thousand Oaks, CA: Sage.

Mallik-Kane, C., \& Visher, C. A. (2008). Health and prisoner reentry: How physical, mental, and substance abuse conditions shape the process of reintegration. Washington, DC: The Urban Institute. http://www.urban.org/UploadedPDF/411617_health_ prisoner reentry.pdf

McKean, L., \& Raphael, J. (2002). Drugs, crime, and consequences: Arrests and incarceration in North Lawndale. Chicago: Center for Impact Research.

McNeill, F. (2000). Defining effective probation: Frontline perspectives. The Howard Journal of Criminal Justice, 39(4), 382-397. DOI: 10.1111/14682311.00177

Miller, J. M. (2014). Identifying collateral effects of offender reentry programming through evaluative field work. American Journal of Criminal Justice, 39(1), 41-58.DOI: 10.1007/s12103-013-9206-6

Miller, H. V., \& Miller, J. M., (2010). Community inreach through jail reentry: Findings from a quasi-experimental design. Justice Quarterly, 27(6), 893-910. DOI: 10.1080/07418825.2010.482537

Mouzon, F. (2008). Forgive us our trespasses: The need for federal expungement legislation.

The University of Memphis Law Review, 39(1), 1-46.

Nagin, D., \& Waldfogel, J. (1993). The effect of conviction on income through the life cycle. NBER Working Paper Series No. 4551.

National Research Council. (2004). Explaining police behavior: Organizations and context.

InW. Skogan \& K. Frydl, Fairness and effectiveness in policing: The evidence (pp. 155-216).

Washington, D. C.: National Academic Press.

Paylor, I. (1995). Housing needs of ex-offenders. Aldershot, UK: Avebury.

Petersilia, J. (2003). When prisoners come home: Parole and prisoner reentry. New York: Oxford University Press.

Pijoan, E. L. (2014). Legal protections against criminal background checks in Europe. Punishment and Society, 16(1), 50-73. DOI: 10.1177/1462474513506031

Pinard, M. (2010). Reflections and perspectives on reentry and collateral consequences. Journal of Criminal Law and Criminology, 100(3), 1213-1224.

Prendergast, M. L., Wellisch, J., \& Wong, M. M. (1996). A study of women on parole who graduated from the Forever Free substance abuse program: Treatment experiences, needs, and services, out- comes. Los Angeles, CA: Drug Abuse Research Center.

Queralt, M. (1996). The social environment and human behavior: A diversity perspective. Needham Heights, MA: Allyn \& Bacon.

Reentry Policy Council. (2011). Second Chance Act. Justice Center, Council of State Government. http:// reentrypolicy.org.

Rodriguez, N., \& Brown, B. (2001). Preventing homelessness among those living prisons. Vera Institute of Justice.

Roman, C. G., \& Travis, J. (2004). Taking stock: Housing, homelessness, and prisoner reentry. Washington, DC: The Urban Institute. http://shnny. org/uploads/Taking_Stock.pdf

Saliba, A. M. (2013). The National Police Certificate is a significant barrier to employment for ex-offenders. European Journal of Probation, 5(1), 23-43.

Schnittker, J. (2004). Social distance in the clinical encounter: Interactional and sociodemographic foundations for mistrust in physicians. Social Psychology Quarterly, 67, 217-235.DOI: 10.1177/019027250406700301.

Seiter, R. P. (2002). Prisoner reentry and the role of parole officers. Federal Probation, 66, 50-54.

Settles, T. (2009). Restorative reentry: A strategy to improve reentry outcomes by enhancing social capital. Victims and Offenders, 4, 285-302. DOI: $10.1080 / 15564880903048560$

Scott-Hayward, C. S. (2009). The fiscal crisis in corrections: Rethinking policies and practices.

New York: Vera Institute of Justice.

Shinkfield, A. J., \& Graffam, J. (2009). Community reintegration of ex-prisoners: Type and degree of change in variables influencing successful reintegration. International Journal of Offender Therapy and Comparative Criminology, 53(1), 29-42.

DOI: $10.1177 / 0306624 X 07309757$

Starr, R. (2002). A successful reintegration into the community: One NGRI acquittee's story. Federal Probation, 66, 59-63.

Steffensmeir, D. J, \& Kramer, J. H. (1980). The differential impact of criminal stigmatization on male and female felons. Sex Roles, 6, 1-8. DOI: 10.1007/BF00288357

Swanson, C. (2009). Restorative justice in a prison community: Or everything I didn't learn in kindergarten I learned in prison. Lanham, MD: Lex ington Books.

Taxman, F. (2011). The cattle call of reentry: Not all processes are equal. Criminology \& Public Policy, 10(4), 925-937. DOI: 10.1111/j.1745- 
9133.2011.00780.x

Tewksbury, R. (2005). Collateral consequences of sex offender registration. Journal of Contemporary Criminal Justice, 21, 67-81. DOI:

$10.1177 / 1043986204271704$

Tewksbury, R., Connor, D. P., Cheeseman, K., \& Rivera, B. L. (2012). Female sex offenders' anticipations for re-entry: Do they really know what they're in for? Journal of Crime and Justice 35(3), 451-463. DOI: 10.1080/0735648X.2012.691240

Travis, J. (2001). But they all come back: Rethinking prisoner reentry. Corrections Management Quarterly, 5(3), 23-33.

Travis, J. (2005). But they all come back: Facing the challenges of prisoner reentry.

Washington, DC: Urban Institute.

Turner, M. A., Fix, M., \& Struyk, R. J. (1991). Hiring discrimination against black men. Urban Institute Policy and Research Report (Summer), 4-5.

Van Ness, D., \& Strong, K. H. (2010). Restoring justice, 4th ed. Cincinnati, OH: Anderson.
Visher, C. (2007). Returning home: Emerging findings and policy lessons about prisoner reentry. Federal Sentencing Reporter, 20(2), 93-102.

DOI: $10.1525 /$ fsr.2007.20.2.93

Visher, C., Baer, D., \& Naser. R. (2006). Ohio prisoners' reflections on returning home. The Urban Institute: Washington, D.C.

Visher, C. LaVigne, N., \& Travis, J. (2004). Returning home: Understanding the challenges of prisoner reentry. The Urban Institute. Washington, D. C.

Weatherspoon, F. D. (1996). Remedying employment discrimination against African-American males: Stereotypical biases engender a case of race plus sex discrimination. Washburn Law Journal, 36(1), 23-87.

Whelan, C. (1973). Civil disabilities: The punishment does not fit the crime. New York: Community Society of New York.

Elaine Gunnison is an Associate Professor in Criminal Justice at Seattle University. Her research specializations include offender reentry, corrections, criminology, and female offending.

Jacqueline B. Helfgott is a Professor in Criminal Justice at Seattle University. Her research specializations include criminal behavior, psychopathy, corrections, offender reentry, victim impact in criminal justice decisionmaking, and restorative justice.

Cecilie Wilhelm is an M.A. student at Seattle University. Her research interests are in offender reentry and harm reduction programming for offenders. 